\title{
TERAPIA COM DISPOSITIVO INTEROCLSUAL EM PACIENTES COM PRÓTESE TOTAL DUPLA COM CEFALÉIA TIPO TENSÃO: SÉRIE DE CASOS
}

Annamaria Ferreira SBARAINI; Daniel BONOTTO; Paulo Afonso CUNALI.

A correlação entre cefaléias e disfunção temporomandibular (DTM) é um achado freqüente. $\mathrm{O}$ objetivo deste trabalho é avaliar a resposta de pacientes com cefaléia tipo tensão, portadores de prótese total dupla, à terapia com dispositivo interoclusal. Foram avaliados cinqüenta pacientes portadores de prótese total dupla, dos quais, oito apresentavam cefaléia diária e queixa de DTM muscular pelos critérios do Reasearch Diagnostic Criteria (RDC). Os oito pacientes foram tratados com dispositivo interoclusal a fim de melhorar a posição ortopédica da mandíbula. Após um período de 45 dias todos os pacientes apresentaram remissão total para queixa de dor temporomandibular e de cefaléia diária. Os resultados permitem concluir que a cefaléia tipo tensão de manifestação diária nesses pacientes tinha íntima relação com a DTM muscular. Além disso, o re-equilíbrio ortopédico promovido pelo dispositivo interoclusal mostrou-se efetivo no controle da sintomatologia nos pacientes avaliados. Sugere-se que a avaliação funcional dos músculos da mastigação e a investigação da queixa de cefaléia seja um procedimento de rotina no exame de pacientes portadores de prótese total. 